\title{
CARACTERIZAÇÃO FÍSICA DOS RESÍDUOS SÓLIDOS DE PALMAS- TO DESTINADOS AO ATERRO SANITÁRIO MUNICIPAL
}

\author{
Thaysi Castro Coelho ${ }^{1}$ \\ Renan Alencar ${ }^{1}$ \\ Rafael Montanhini Soares de Oliveira ${ }^{2}$
}

RESUMO: O crescimento da população juntamente com o aumento da atividade humana tem provocado um aumento acelerado na geração de resíduos sólidos que traz consequências ao meio ambiente e à qualidade de vida da população. No Brasil, o manejo e disposição desses resíduos ainda são feitos de maneira ineficiente sendo que os "lixões" são a forma de destino final dos resíduos sólidos para a maioria dos municípios. As características dos resíduos sólidos podem variar em função de aspectos sociais, econômicos, culturais, geográficos e climáticos e o estudo dessas características faz-se necessário para possibilitar um melhor gerenciamento público para este setor do saneamento básico. A caracterização física dos resíduos sólidos é muito importante para a gestão adequada dos serviços de limpeza e pode ser facilmente determinada através de amostragens em campo. Com isso pôde se estimar uma geração per capita de resíduos sólidos de 0,898 kg/hab.dia no ano de 2010 para a cidade de Palmas-TO. Os quarteamentos feitos nas amostragens definiram a composição gravimétrica dos resíduos sólidos destinados ao aterro sanitário o que mostrou as maiores quantidades de matéria orgânica tanto para o período seco, $79,6 \%$, quanto para o período chuvoso, $59,6 \%$ do total de lixo, seguida pelos componentes papeis e plásticos.

Palavras chave: Resíduos Sólidos Urbanos, Aterro Sanitário, Caracterização Física.

\section{1 - INTRODUÇÃO}

O lixo urbano é um dos problemas mais sérios enfrentados pela comunidade atualmente. Esse problema se relaciona diretamente com o crescimento constante da população, contribuindo assim, para o aumento dos resíduos sólidos, com

\footnotetext{
${ }^{1}$ Graduado em Engenharia Ambiental - Universidade Federal do Tocantins

${ }^{2}$ Doutor em Engenharia Química - Universidade Federal do Tocantins - Docente e-mail: montanhini@uft.edu.br
} 


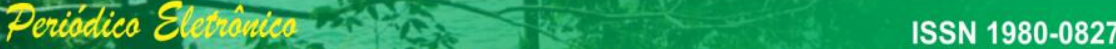

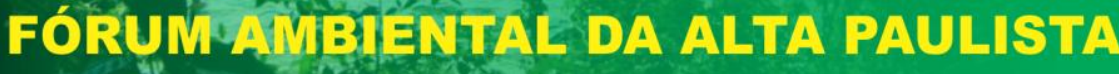 \\ V. 07, N. 12, 2011 - Categoria: Artigo Completo \\ Instituição Organizadora: ANAP - Associação Amigos da Natureza da Alta Paulista}

consequências desastrosas para o meio ambiente e para a qualidade de vida da coletividade (FONSECA, 1999).

Mesmo com todas as pesquisas feitas sobre resíduos sólidos urbanos (RSU) no Brasil os resultados apresentam uma enorme discrepância, principalmente no que diz respeito ao lixo gerado e o lixo coletado.

De acordo com o IBGE (2008) o manejo dos resíduos sólidos (que inclui coleta e destinação final do lixo e limpeza pública) passou a existir em todos os municípios em 2008, frente a 99,4\% deles em 2000. Em oito anos de dados de pesquisa, o percentual de municípios que destinavam seus resíduos a vazadouros a céu aberto caiu de $72,3 \%$ para $50,8 \%$, enquanto os que utilizavam aterros sanitários cresceram de $17,3 \%$ para $27,7 \%$.

O Brasil produziu 29.629.736 toneladas de RSU durante o ano de 2007, com 306 municípios consultados pela Pesquisa Nacional de Saneamento Básico (IBGE, 2008). Os vazadouros a céu aberto, conhecidos como "lixões", ainda são o destino final dos resíduos sólidos em 50,8\% dos municípios brasileiros, mas esse quadro teve uma mudança significativa nos últimos 20 anos: em 1989, eles representavam o destino final de resíduos sólidos em $88,2 \%$ dos municípios. As regiões Nordeste $(89,3 \%)$ e Norte $(85,5 \%)$ registraram as maiores proporções de municípios que destinavam seus resíduos aos lixões, enquanto as regiões Sul $(15,8 \%)$ e Sudeste $(18,7 \%)$ apresentaram os menores percentuais. Paralelamente, houve uma expansão no destino dos resíduos para os aterros sanitários, solução mais adequada, que passou de 17,3\% dos municípios, em 2000, para 27,7\%, em 2008.

Segundo o IBAM (2005), 47\% dos resíduos sólidos urbanos coletados são destinados em aterros sanitários, 23,3 \% em aterros controlados, 30,5\% em lixões, $0,4 \%$ na forma de compostagem e $0,1 \%$ em triagem.

O Instituto Brasileiro de Administração Municipal (2005) relata que, esses dados referem-se às porcentagens do lixo coletado. Observando as porcentagens relativamente ao número de municípios, verificamos que a maioria destes ainda tem lixões. As porcentagens indicadas pelas pesquisas apontam que $59 \%$ dos municípios dispõem seus resíduos sólidos em lixões, 13\% em aterros sanitários, $17 \%$ em aterros controlados, 0,6\% em áreas alagadas, 0,3\% têm aterros especiais, 
2,8\% têm programas de reciclagem, 0,4\% promovem compostagem e 0,2\% realizam incineração.

A Política Nacional de Resíduos Sólidos - Lei n 12.305 de 2 de agosto de 2010 discorre sobre "princípios, objetivos e instrumentos, bem como sobre as diretrizes relativas à gestão integrada ao gerenciamento de resíduos sólidos, incluídos os perigosos, às responsabilidades dos geradores e do poder público e aos instrumentos econômicos aplicáveis" que esta lei estabelece (BRASIL, 2010).

O aterro sanitário de Palmas-TO está localizado à $26 \mathrm{~km}$ do centro da cidade em uma área rural chamada assentamento São João. Recebe em média de 120 a 130 toneladas de lixo por dia, e sua área é de 95 hectares, sendo utilizados somente 9,8 hectares (FINCO, VALADARES e SILVA, 2006).

O objetivo deste trabalho é analisar as características do lixo da cidade de Palmas-TO que é destinado a aterro sanitário municipal.

\section{2 - MATERIAL E MÉTODOS}

\subsection{Localização da área de estudo}

O Aterro Sanitário de Palmas está localizado na área rural do município, na parte sul do mesmo, distante aproximadamente $25 \mathrm{~km}$ do centro do Plano Diretor, com uma área de 95,7784 hectares (COELHO, 2010).

\subsection{Determinação das principais características físicas}

A realização deste trabalho metodologia utilizada foi a contida no Manual Gerenciamento Integrado de Resíduos Sólidos (MONTEIRO et al., 2001) com algumas adaptações.

Para tanto, utilizou-se os seguintes materiais:

- 01 Tambor com capacidade para 200 litros;

- Balança com capacidade para 300 kg;

- 02 Enxadas; 
- 01 Pá;

- Máscaras de proteção respiratória com filtro;

- Luvas sanitárias para o manuseio do lixo;

- Botas de borracha.

Os procedimentos práticos apresentados a seguir serviram para a determinação do peso específico, composição gravimétrica, e geração per capita do lixo urbano.

\subsubsection{Preparo da amostra}

Coletou-se inicialmente amostras com cerca de $3 \mathrm{~m}^{3}$ de volume, a partir de lixo não compactado (lixo solto). A primeira coleta foi feita entre os dias 13 a 16 de setembro de 2010 (segunda e quinta-feira respectivamente) e selecionadas de diferentes setores de coleta, a fim de se conseguir resultados que se aproximassem o máximo possível da realidade;

Colocou-se as amostras iniciais sobre uma área plana, e misturou-as com o auxílio de pás e enxadas e também com o auxílio do trator até se obter um único lote homogêneo, rasgando-se os sacos plásticos, caixas de papelão, caixotes e outros materiais utilizados no acondicionamento dos resíduos;

Dividiu-se a fração de resíduos homogeneizada em quatro partes, selecionando dois dos quartos resultantes que foram novamente misturados e homogeneizados.

Repetiu-se o procedimento anterior até que o volume de cada um dos quartos ficasse de aproximadamente de $1 \mathrm{~m}^{3}$ e separou-se um dos quartos para preencher 0 latão de 200 litros, previamente pesado.

Ao final levou-se para o aterro todo o lixo que sobrou desta operação.

\subsubsection{Determinação do peso específico aparente}


Pesou-se o latão cheio do lixo não compactado e determinou-se o peso do lixo, descontando o peso do latão.

Determinou-se o peso específico aparente através do valor da obtido dividindo pelo volume do tambor e expresso em $\mathrm{kg} \cdot \mathrm{m}^{-3}$.

\subsubsection{Determinação da composição gravimétrica}

De acordo com o objetivo que se pretendia alcançar, determinou-se a lista dos componentes que se pretendia determinar sendo: matéria orgânica, papel/papelão, plásticos, vidros, metais e "outros".

Espalhou-se o material do latão sobre uma área, plana em seguida separouse o lixo por cada um dos componentes desejados;

Classificou-se como "outros" qualquer material encontrado que não se enquadrou na listagem de componentes pré-selecionada, e depois pesou-se cada componente separadamente .

Dividiu-se o peso de cada componente pelo peso total da amostra e calculouse a composição gravimétrica em termos percentuais.

\subsubsection{Cálculo da geração per capita}

Com os dados obtidos da balança do aterro, pôde-se determinar a quantidade de lixo coletado e encaminhado ao aterro durante do ano de 2010, sendo analisado a cada mês. Em seguida avaliou-se o percentual da população atendida pelo serviço de coleta.

O cálculo da taxa de geração per capita foi realizado dividindo-se o peso do lixo pela população atendida.

\section{3 - RESULTADOS E DISCUSSÕES}

\subsection{Rotas do lixo de Palmas}




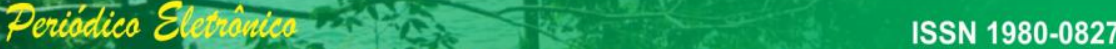

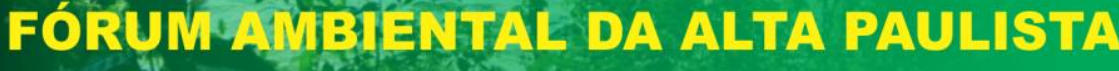 \\ V. 07, N. 12, 2011 - Categoria: Artigo Completo \\ Instituição Organizadora: ANAP - Associação Amigos da Natureza da Alta Paulista}

Pelos dados obtidos na Agência de Serviços Públicos de Palmas-TO (AGESP) identificou-se 27 rotas dos caminhões que fazem a coleta do lixo que atendem toda a cidade de Palmas-TO.

Estas são divididas quanto ao turno e dias da semana sendo:

- 07 Rotas Diurnas - Segunda, quarta e sexta;

- 07 Rotas Diurnas - Terça, quinta e sábado;

- 06 Rotas Noturnas - Segunda, quarta e sexta;

- 05 Rotas Noturnas - Terça, quinta e sábado; e

- 02 Rotas Diárias - Segunda, Terça, Quarta, Quinta, Sexta e Sábado.

Pela quantidade de lixo de algumas rotas, as coletas são repetidas diariamente. Isso é feito nas quadras centrais: 103 Norte, 103 Sul, 104 Norte e 104 Sul; nas principais avenidas da cidade: Av. Teotônio Segurado, Av. Juscelino Kubitschek, Av. LO-27 e Av. Tocantins; além das Secretarias e Rodoviária.

E pela pouca quantidade de lixo o sistema de coleta é feito apenas às terças e sábados nos Setores Taquari e Aeroporto.

\subsection{Peso específico aparente e composição gravimétrica do lixo de Palmas- TO.}

De acordo com os levantamentos realizados em campo, foi possível determinar a composição gravimétrica do lixo coletado na cidade de Palmas-TO.

Foram feitos dois levantamentos de campo sendo que o primeiro foi realizado entre os dias 13 a 16 de setembro de 2010 representando o final da estação seca; e o segundo, realizado nos dias 27 e 28 de abril de 2011, representando o final da estação chuvosa.

\subsubsection{Peso específico aparente.}

O peso específico aparente do lixo foi obtido a partir do resultado observado na balança. Após pesado, dividiu-se pelo volume de 200 litros do latão. O peso específico aparente em $\mathrm{kg} / \mathrm{m}^{3}$ obtendo os seguintes resultados: 


\section{Periódica

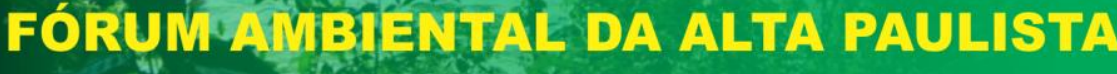 \\ V. 07, N. 12, 2011 - Categoria: Artigo Completo \\ Instituição Organizadora: ANAP - Associação Amigos da Natureza da Alta Paulista}

$\mathrm{Na}$ primeira amostragem realizada em setembro determinou-se o peso específico aparente dos resíduos sólidos representada na Tabela 1.

Tabela 1 - Peso específico aparente da primeira amostragem.

\begin{tabular}{|l|l|l|}
\hline Data & Rota & Peso específico aparente $\left(\mathrm{kg} / \mathrm{m}^{3}\right)$ \\
\hline 13.09 .10 & Diurna & 190,0 \\
\hline 14.09 .10 & Diurna & 190,0 \\
\hline 15.09 .10 & Noturna & 194,0 \\
\hline 16.09 .10 & Noturna & 169,0 \\
\hline
\end{tabular}

$\mathrm{Na}$ segunda amostragem (Tabela 2), realizada em abril obteve-se os seguintes resultados.

Tabela 2 - Peso específico aparente da segunda amostragem.

\begin{tabular}{|l|l|l|}
\hline Data & Rota & Peso específico aparente $\left(\mathrm{kg} / \mathrm{m}^{3}\right)$ \\
\hline 27.04 .11 & 02 (Diurna) & 295,0 \\
\hline 28.04 .11 & 01 (Diurna) & 212,0 \\
\hline
\end{tabular}

A média do peso específico aparente para a amostragem feita em setembro foi de $185,75 \mathrm{~kg} \cdot \mathrm{m}^{-3}$ enquanto a média do peso específico aparente para a amostragem feita em abril foi de $253,5 \mathrm{~kg} \cdot \mathrm{m}^{-3}$. Esta diferença pode ser explicada pela sazonalidade quando comparamos as estações de seca e chuva.

\subsubsection{Composição gravimétrica.}

As Tabelas a seguir mostram a composição gravimétrica do lixo de PalmasTO.

Tabela 3 - Composição gravimétrica do dia 13 de setembro de 2010. 


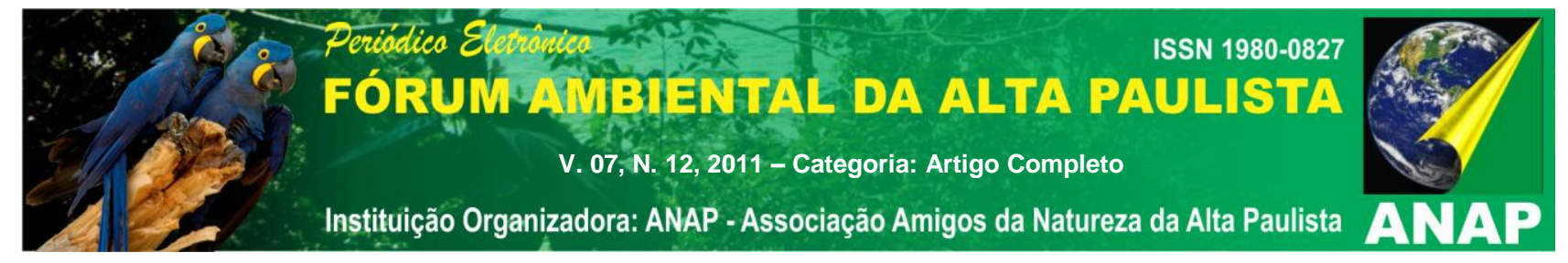

\begin{tabular}{|l|r|r|}
\hline Componentes & Massa (kg) & Porcentagem (\%) \\
\hline Matéria Orgânica & 30,6 & 80,53 \\
\hline Papel/Papelão & 1,2 & 3,16 \\
\hline Plásticos & 3,0 & 7,89 \\
\hline Vidros & 0,0 & 0,00 \\
\hline Metais & 2,7 & 7,11 \\
\hline Outros & 0,5 & 1,32 \\
\hline Total & 38,0 & 100,00 \\
\hline
\end{tabular}

Tabela 4 - Composição gravimétrica do dia 14 de setembro de 2010.

\begin{tabular}{|l|l|r|}
\hline Componentes & Massa $(\mathrm{kg})$ & Porcentagem (\%) \\
\hline Matéria Orgânica & 34,8 & 91,58 \\
\hline Papel/Papelão & 1,0 & 2,63 \\
\hline Plásticos & 1,5 & 3,95 \\
\hline Vidros & 0,0 & 0,00 \\
\hline Metais & 0,2 & 0,53 \\
\hline Outros & 0,5 & 1,32 \\
\hline Total & 38,0 & 100,0 \\
\hline
\end{tabular}

Tabela 5 - Composição gravimétrica do dia 15 de setembro de 2010.

\begin{tabular}{|l|r|r|}
\hline Componentes & Massa $(\mathrm{kg})$ & Porcentagem (\%) \\
\hline Matéria Orgânica & 29,0 & 74,74 \\
\hline Papel/Papelão & 4,8 & 12,37 \\
\hline Plásticos & 4,6 & 11,86 \\
\hline Vidros & 0,2 & 0,52 \\
\hline Metais & 0,1 & 0,26 \\
\hline Outros & 0,1 & 0,26 \\
\hline Total & 38,8 & 100,0 \\
\hline
\end{tabular}




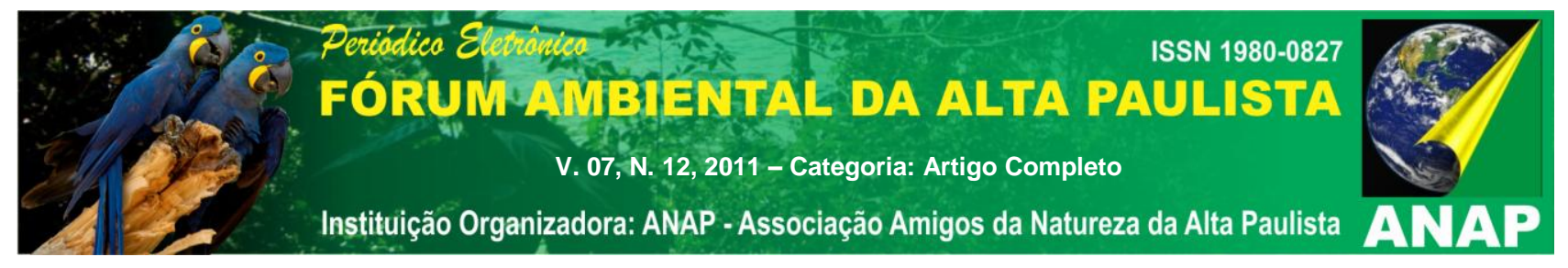

Tabela 6 - Composição gravimétrica do dia 16 de setembro de 2010.

\begin{tabular}{l|l|}
\hline Componentes & \\
\hline Matéria Orgânica \\
\hline Papel/Papelão \\
\hline Plásticos \\
\hline Vidros \\
\hline Metais \\
\hline Outros \\
\hline Total
\end{tabular}

\begin{tabular}{|r|r|}
\hline Massa $(\mathrm{kg})$ & Porcentagem (\%) \\
\hline 23,9 & 70,71 \\
\hline 3,3 & 9,76 \\
\hline 5,0 & 14,79 \\
\hline 0,2 & 0,59 \\
\hline 1,0 & 2,96 \\
\hline 0,4 & 1,18 \\
\hline 33,8 & 100,0 \\
\hline
\end{tabular}

No segundo levantamento de campo obteve-se os seguintes resultados:

Tabela 7 - Composição gravimétrica do dia 27 de abril de 2011.

\begin{tabular}{|l|r|r|}
\hline Componentes & Massa $(\mathrm{kg})$ & \\
\hline Matéria Orgânica & 32,6 & 55,25 \\
\hline Papel/Papelão & 6,3 & 10,68 \\
\hline Plásticos & 10,1 & 17,12 \\
\hline Vidros & 0,0 & 0,00 \\
\hline Metais & 1,3 & 2,20 \\
\hline Outros & 8,8 & 14,92 \\
\hline Total & 59,0 & 100,0 \\
\hline
\end{tabular}

Tabela 8 - Composição gravimétrica do dia 28 de abril de 2011.

\begin{tabular}{l} 
Componentes \\
\hline Matéria Orgânica \\
\hline Papel/Papelão \\
\hline Plásticos \\
\hline Vidros \\
\hline Metais
\end{tabular}

\begin{tabular}{|r|r|}
\hline Massa $(\mathrm{kg})$ & Porcentagem (\%) \\
\hline 26,9 & 63,44 \\
\hline 7,3 & 17,22 \\
\hline 3,3 & 7,78 \\
\hline 0,7 & 1,65 \\
\hline 0,3 & 0,71 \\
\hline
\end{tabular}



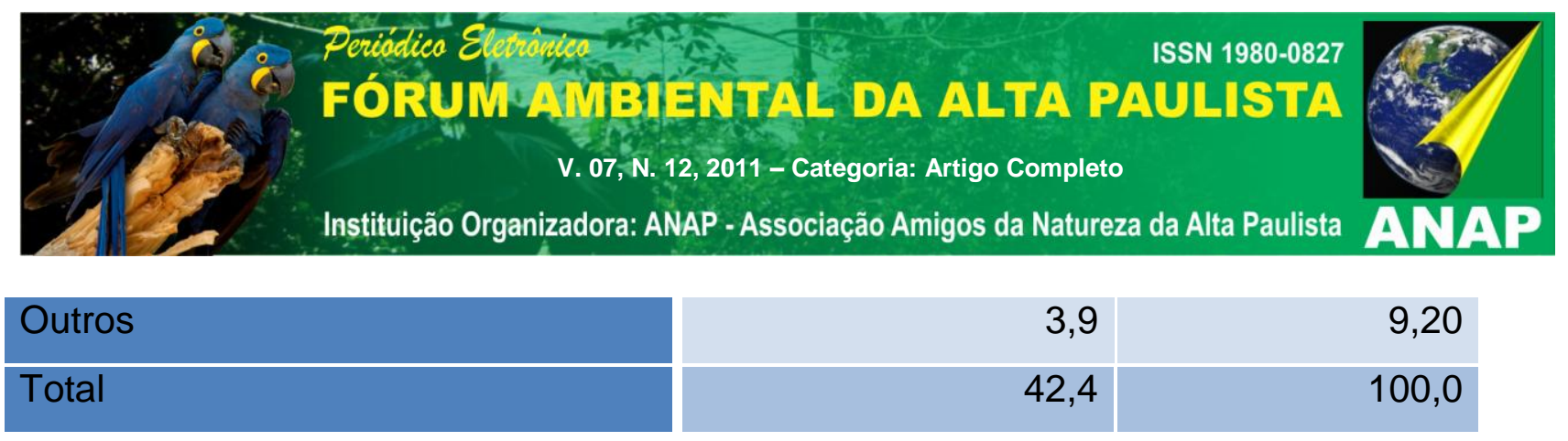

A matéria orgânica apresentou os maiores valores tanto no período de seca quanto no período chuvoso com mais de $50 \%$ do total de lixo. Para o período de seca este índice variou de $70,71 \%$ a $91,58 \%$, já no período de chuva este índice variou de $55,25 \%$ e $63,44 \%$.

A baixa quantidade de metais e vidros, tanto no período de seca como no período chuvoso deve-se ao trabalho dos "catadores" desses materiais para as usinas de reciclagem.

Para representar a realidade do Município de Palmas foi realizada uma média aritmética dos resultados obtidos. Os gráficos a seguir referem-se às análises realizadas das duas amostragens, uma no período de seca, que compreende os meses de abril a setembro, e uma outra no período de chuva, compreendendo os meses de outubro a março:

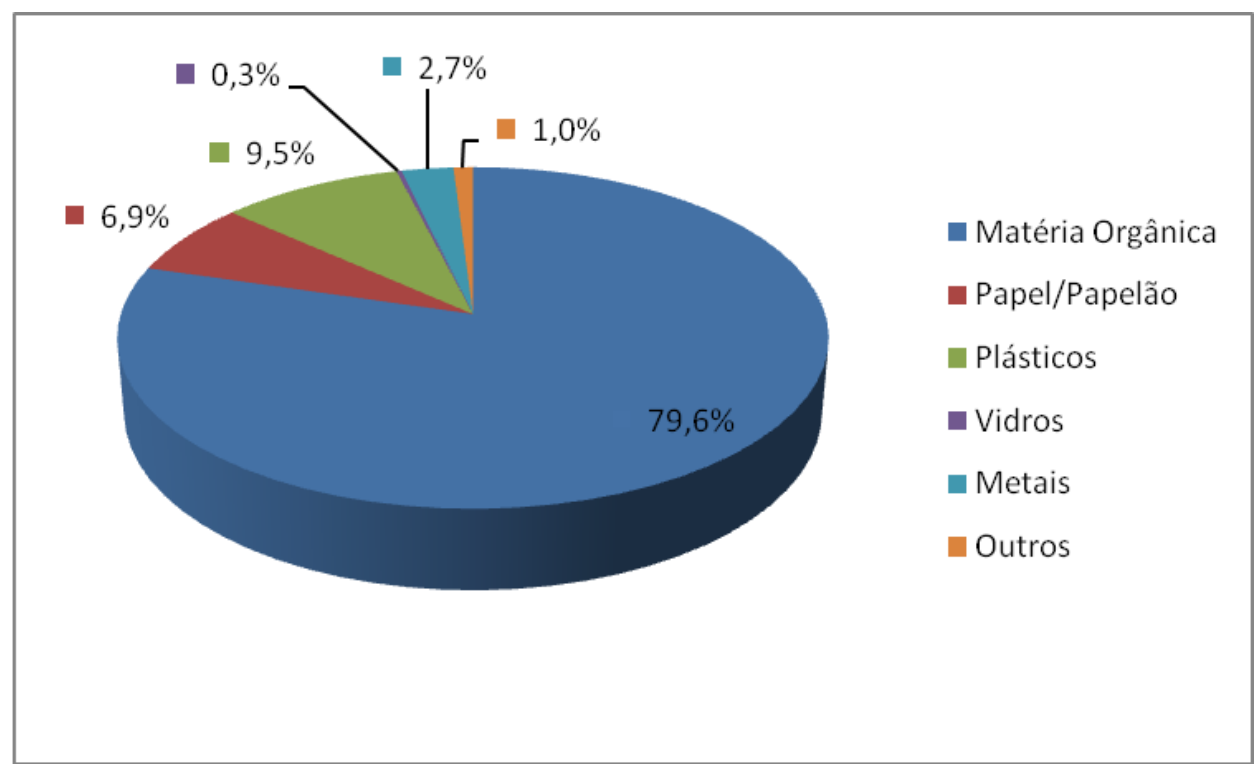

Figura 2 - Média do quarteamento realizado na primeira amostragem em setembro. 

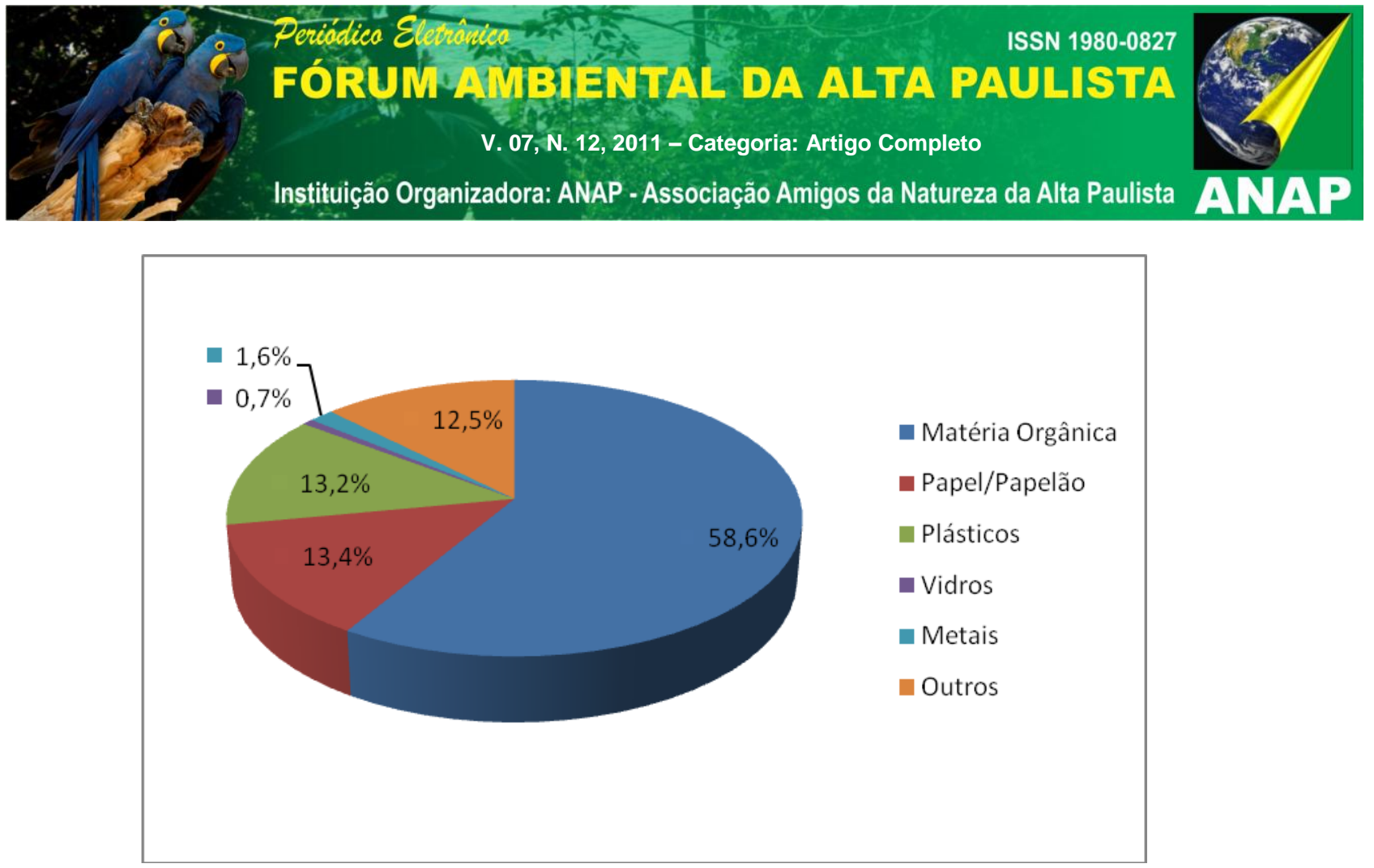

Figura 3 - Média do quarteamento realizado na segunda amostragem em abril.

\subsection{Cálculo da geração per capita}

Segundo o último censo do IBGE (2010) a população palmense atinge o número de 228.332 habitantes e de acordo com os dados obtidos através da balança do aterro chegou-se a quantia de $74.816 .402 \mathrm{~kg}$ de lixo no ano de 2010 .

Portanto o cálculo da geração per capita de resíduos sólidos para a cidade de Palmas no ano de 2010 se chegou ao seguinte resultado (Tabela 9):

Tabela 9 - Geração per capita de resíduos sólidos de Palmas - TO no ano de 2010.

\begin{tabular}{|l|l|l|}
\hline \multicolumn{1}{|c|}{ Mês } & \multicolumn{1}{|c|}{ Massa de lixo (kg) } & \multicolumn{1}{|c|}{$\begin{array}{c}\text { Geração per capita } \\
\text { (kg/hab.dia) }\end{array}$} \\
\hline Janeiro & 5744922 & 0,811625 \\
\hline Fevereiro & 5789799 & 0,905605 \\
\hline Março & 6351335 & 0,897298 \\
\hline Abril & 6069264 & 0,886029 \\
\hline Maio & 5240260 & 0,740328 \\
\hline Junho & 5428028 & 0,792417 \\
\hline Julho & 5264955 & 0,743817 \\
\hline
\end{tabular}




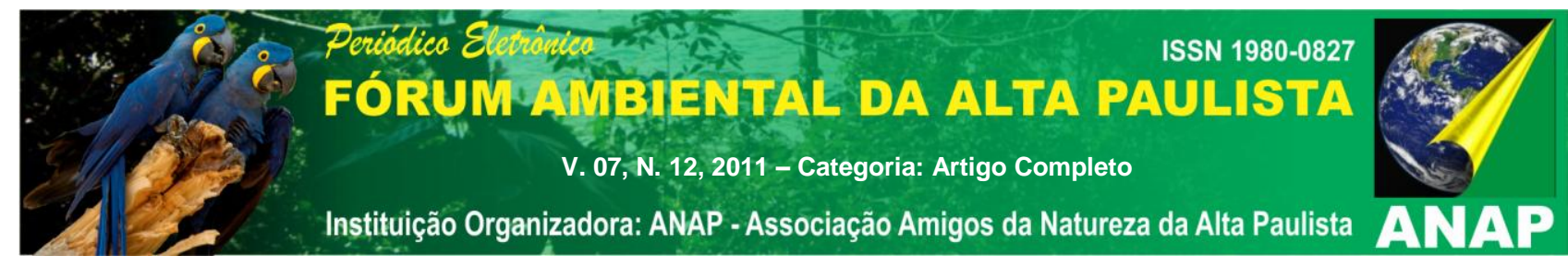

\begin{tabular}{|l|l|l|}
\hline Agosto & 5562199 & 0,785811 \\
\hline Setembro & 7079634 & 1,033529 \\
\hline Outubro & 6927703 & 0,978725 \\
\hline Novembro & 7112889 & 1,038384 \\
\hline Dezembro & 8245414 & 1,164888 \\
\hline
\end{tabular}

Notou-se que durante o ano, a geração per capita variou bastante podendo ser dividido em três quadrimestres distintos:

De janeiro a abril, com geração per capita que variou de 0,81 a 0,90 $\mathrm{kg} / \mathrm{hab}$.dia. De maio a agosto a geração per capita variou de 0,74 a $0,79 \mathrm{~kg} / \mathrm{hab}$.dia. E de setembro a dezembro, variou de 0,97 a $1,16 \mathrm{~kg} / \mathrm{hab}$.dia.

Para o ano de 2010 a média foi de $0,898 \mathrm{~kg}$ de resíduos sólidos produzido por dia por habitante na cidade de Palmas-TO.

\section{4 - CONCLUSÃO}

A partir dos resultados obtidos foi possível chegar as seguintes conclusões:

- O peso específico aparente dos resíduos sólidos coletados e dispostos no aterro sanitário de Palmas se mostrou com uma diferença significante em relação às duas amostragens realizadas. Pôde-se notar um aumento no peso específico aparente das amostras coletadas na segunda amostragem, de abril, em relação ao peso específico aparente da primeira amostragem, de setembro. Este fato deve-se principalmente a sazonalidade dos períodos de seca e chuva.

- A composição gravimétrica também se mostrou com uma diferença significativa em relação aos meses de setembro e abril sendo que o primeiro apresentou uma quantidade de matéria orgânica de $79,6 \%$ do total de resíduos coletados da amostra enquanto o segundo apresentou uma média de $58,6 \%$.

- A baixa quantidade de papeis, plásticos e metais pode estar associado ao fato de que em Palmas existem associações de "catadores" que comercializam 


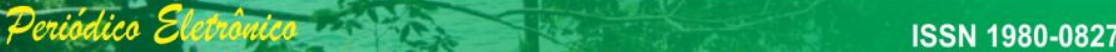 \\ FÓRUM \\ V. 07, N. 12, 2011 - Categoria: Artigo Completo \\ Instituição Organizadora: ANAP - Associação Amigos da Natureza da Alta Paulista}

este tipo de material com as empresas de reciclagem.

- A geração per capita de resíduos sólidos da cidade de Palmas mostrou-se acima da faixa estipulada para cidades de 30 mil a 500 mil habitantes com cercad de 0,89 kg/hab.ano.

- De acordo com a empresa responsável pela coleta de lixo na cidade de Palmas as rotas dos caminhões que fazem a coleta de lixo abrangem todos os bairros da cidade. A coleta de lixo é feita de acordo com um calendário semanal divido em 27 rotas.

\section{REFERÊNCIAS}

ABNT - Associação Brasileira de Normas Técnicas. Resíduos Sólidos: classificação. NBR 10.004. Rio de Janeiro, 2004.

BIDONE, F. R. A.; POVINELLI, J. Conceitos Básicos de Resíduos Sólidos. São Carlos: EESC/USP, 1999.

BRASIL. Lei no 12.305, de 2 de agosto de 2010. Institui a Política Nacional de Resíduos Sólidos; altera a Lei 9605, de 12 de fevereiro de 1998; e dá outras providências. Diário Oficial [da] República Federativa do Brasil, Brasília, DF, 3 de agosto de 2010. Disponível em: <http://www.in.gov.br>. Acesso em: 17 ago. 2010.

COELHO, Thaysi Castro. Estimativa teórica da geração de metano no aterro sanitário de Palmas-TO. 2010, 63p. Trabalho de Conclusão de Curso (Graduação em Bacharel em Engenharia Ambiental, Fundação Universidade Federal do Tocantins, Palmas,TO).

FINCO, M. V. A.; VALADARES, M. B.; SILVA, M. A. Gestão de Resíduos Sólidos na Cidade de Palmas/TO: Contribuições ao Mecanismo de Desenvolvimento Limpo (MDL). 2006. Disponível em: <http://www.sober.org.br/palestra/6/832.pdf>. Acesso em: 26 ago 2010.

FONSECA, E. Iniciação ao Estudo dos Resíduos Sólidos e da Limpeza Urbana: A União. 1999. 122p.

FUZARO, J. A.; RIBEIRO, L. T. Coleta Seletiva para Prefeituras. 4a ed. São Paulo: SMA/CPLEA, 2005.

IBAM. Cenário dos Resíduos Sólidos no Brasil. 2005. Disponível em: <http://www.ibam.org.br/publique/media/Boletim1a.pdf>. Acesso em: 15 ago 2010.

IBGE. Pesquisa Nacional de Saneamento Básico. 2000. Disponível em: $<$ http://www.ibge.gov.br/home/estatistica/populacao/condicaodevida/pnsb/pnsb.pdf>. Acesso em: 26 ago 2010.

JURAS, I. A. G. M. Destino dos Resíduos Sólidos e Legislação Sobre o Tema - Nota Técnica. Consultoria Legislativa. Câmara dos Deputados. Brasília-DF. 2001. Disponível em: $<$ http://www.mp.ba.gov.br/atuacao/ceama/material/doutrinas/residuos/destino_dos_residuos_solidos_ e_legislacao_sobre_o_tema.pdf >. Acesso em: 17 ago 2010.

LIMA, J. D. Gestão de resíduos sólidos urbanos no Brasil. ABES. Paraíba, 2004. 


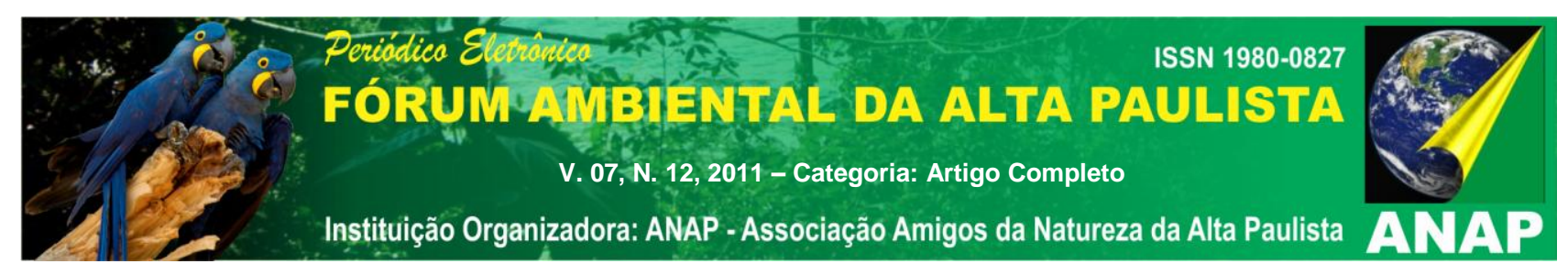

NAVAL, L. P.; GONDIM, S. M.; Caracterização física e físico-química dos resíduos sólidos urbanos domésticos e comerciais da cidade de Palmas-TO. In: CONGRESSO BRASILEIRO DE ENGENHARIA SANITÁRIA E AMBIENTAL, 21. Anais. João Pessoa-PB. 2001.

MESQUITA JÚNIOR, J. M. de; SEGALA, K. (Coord.). Gestão Integrada de Resíduos Sólidos. Rio de Janeiro: IBAM. 2007. 40p. Disponível em: <http://www.ibam.org.br/publique/media/01-girs.pdf>. Acesso em: 19 ago 2010.

MONTEIRO, J. H. P. et al.; ZVEIBIL, V. Z. (Coord.). Manual de Gerenciamento Integrado de Resíduos Sólidos. Rio de Janeiro: IBAM, 2001. Disponível em: <http://www.resol.com.br/cartilha4/>. Acesso em: 16 ago 2010.

PHILIPPI JR, Arlindo ; AGUIAR, Alexandre de Oliveira e . Resíduos Sólidos: Características e Gerenciamento. In: Arlindo Philippi Jr. (Org.). Saneamento, saúde e ambiente: Fundamentos para um desenvolvimento sustentável. 1 ed. Barueri, SP: Manole, 2005, v. 1, p. 267-321 